\title{
THE INVESTIGATION OF TECHNOLOGICAL AND PHYSICO-CHEMICAL CHARACTERISTICS OF ACTIVE SUBSTANCES AND THEIR GRANULATES FOR THE DEVELOPMENT COMBINED DRUG “ANALPHENON"
}

\author{
Yunusova Kholida Mannanovna ${ }^{1}$ \\ ${ }^{1}$ Professor, Department of Industrial Technology of Medicines, Tashkent Pharmaceutical Institute, \\ Tashkent, Uzbekistan
}

\author{
Ravshanova Sevara Ergashevna ${ }^{2}$ \\ ${ }^{2}$ PhD student, Department of Industrial Technology of Medicines, Tashkent Pharmaceutical \\ Institute, Tashkent, Uzbekistan,
}

\begin{abstract}
In order to theoretically substantiate the composition and technology of "Analfenon" capsules, we have studied the basic physicochemical and technological properties of samples of substance and granulates. These properties are interrelated and in a certain way can affect the process of obtaining high-quality capsules with the necessary therapeutic effect. Substance - powder and masses for encapsulation — was subjected to physico-chemical and pharmacotechnological research. The results will serve as the basis for our further research on the development of capsule technology "Analfenon" a.
\end{abstract}

KEY WORDS: capsule, technological properties, fractional composition.

\section{INTRODUCTION}

The dosage form of the drug is no less important than the choice of the drug itself, which is part of successful therapy [2]. Today, the capsule is one of the most common forms of solid medicines after tablets. The solid (two-section, detachable) capsule has always represented modernity and innovation, despite its widespread use in medicine and pharmaceuticals at the end of the 19th century. It has stood the test of time, because it has constantly changed and improved in accordance with the needs of consumers: increasing the speed of filling and automation of production, increasing quality requirements and new types of formulations $[4,5,6]$.

Pharmaceutical factors determine the quality, bioavailability, therapeutic efficacy and safety of drugs. One of them is the production process for the production of dosage forms, which is of particular importance and significance in the development of new drugs and the improvement of compositions and technology [3]. The study of pharmaceutical factors is of practical importance and remains promising. The quality of the capsules substantially depends on a number of technological factors - fractional composition, particle shapes of the pressed material, residual moisture and pressing pressure, which have a significant impact on the technological parameters of granules and the quality indicators of capsules $[1,7]$.

Given the above, an urgent task is to study the technological characteristics of the substance and granulate in order to scientifically-theoretical justify the technology of the capsule.

\section{MATERIALS AND METHODS}

The following raw materials were used in the preparation of this medicine: substance of metamizole sodium, series 0070215, manufactured by Hebei 
Jiheng (Group) Pharmaceutical Co., Ltd (China); substance drotaverine hydrochloride series 14009246 manufactured by "Xian Accenture Biological Technology Co., Ltd" (China); substance diphenhydramine hydrochloride series 150216 manufactured by Xian Accenture Biological Technology Co., Ltd (China); Potato Starch - (BP, Eurph, USP); Calcium stearate - TU 6-09-4233-76.

\section{RESULTS AND DISCUSSION}

Study of the structural and technological properties of the substances "Analfenon".

The study of the size, shape and surface relief of particles and granules of medicinal substances was carried out using an MBI-15 microscope, enlarged 400 times, which allows to characterize the shape and surface of the particles, as well as the average linear size of the dominant fractions.

To select the optimal composition and develop rational capsule technology, it is necessary to have complete information about the physic- chemical, microscopic, and technological properties of drugs. In order to select the optimal technology for producing capsules, at the first stage, the technological characteristics of the substances metamizole sodium, drotaverine hydrochloride, and diphenhydramine hydrochloride were studied. From the results presented in Table 1 , it is seen that the particles of the substance metamizole sodium have the form of powders in the form of prismatic and lamellar, and the particles of the substance drotaverine hydrochloride are mainly cubic and plate crystals, so that the particles of the powder drotaverine hydrochloride are significantly larger than the particles of metamizole sodium. Diphenhydramine hydrochloride mainly consists of crystals in the form of sticks and their fragments. The values of the technological characteristics of these active substances differ significantly. So, metamizole sodium powder, in comparison with other substances, has a low flowability, high bulk density and less compaction.

Table 1

The results of determining the microscopic and technological properties of the substances that make up the capsules

\begin{tabular}{|l|c|c|c|}
\hline \multirow{2}{*}{ Properties } & \multicolumn{2}{|c|}{ Substance } \\
\cline { 2 - 4 } & $\begin{array}{c}\text { Metamizole } \\
\text { sodium }\end{array}$ & $\begin{array}{c}\text { Drotaverine } \\
\text { hydrochloride }\end{array}$ & $\begin{array}{c}\text { Diphenhydramine } \\
\text { hydrochloride }\end{array}$ \\
\hline $\begin{array}{l}\text { Description and shape } \\
\text { of powder particles }\end{array}$ & $\begin{array}{c}\text { white prismatic and } \\
\text { lamellar powder }\end{array}$ & $\begin{array}{c}\text { yellow or light yellow } \\
\text { cubic and plate crystals }\end{array}$ & $\begin{array}{c}\text { white or colorless crystal } \\
\text { wand }\end{array}$ \\
\hline Flowability, $\mathbf{1 0}^{-3} \mathbf{k g} / \mathbf{s}$ & 1,15 & 1,48 & 1,36 \\
\hline Angle of repose, degrees & $54,7 \pm 2,3$ & $32,0 \pm 2,0$ & $42,5 \pm 2,5$ \\
\hline Bulk density, $\boldsymbol{g} /$ cm $^{3}$ & $0,865 \pm 0,033$ & $0,316 \pm 0,035$ & $0,501 \pm 0,025$ \\
\hline Compressibility factor & 1,76 & 1,93 & 1,89 \\
\hline Porosity, \% & 75,29 & 70,68 & 67,81 \\
\hline Moisture content, \% & $4,36 \pm 0,02$ & $0,55 \pm 0,05$ & $2,67 \pm 0,03$ \\
\hline
\end{tabular}

The fractional composition of active substances was studied according to the GF XI method by sieving through a set of sieves with openings of $1000,630,400,315,200,160,100$ and $50 \mu \mathrm{m}$ (Fig. 1). As can be seen from the data presented, a predominantly large amount of metamizole sodium substances $(86.01 \%)$ is represented by a particle size of $-630+160 \mu \mathrm{m}$, for which the average particle size is $395 \mu \mathrm{m}$. 
Figure 1

The results of determining the microscopic and technological properties of the substances that make up the capsules

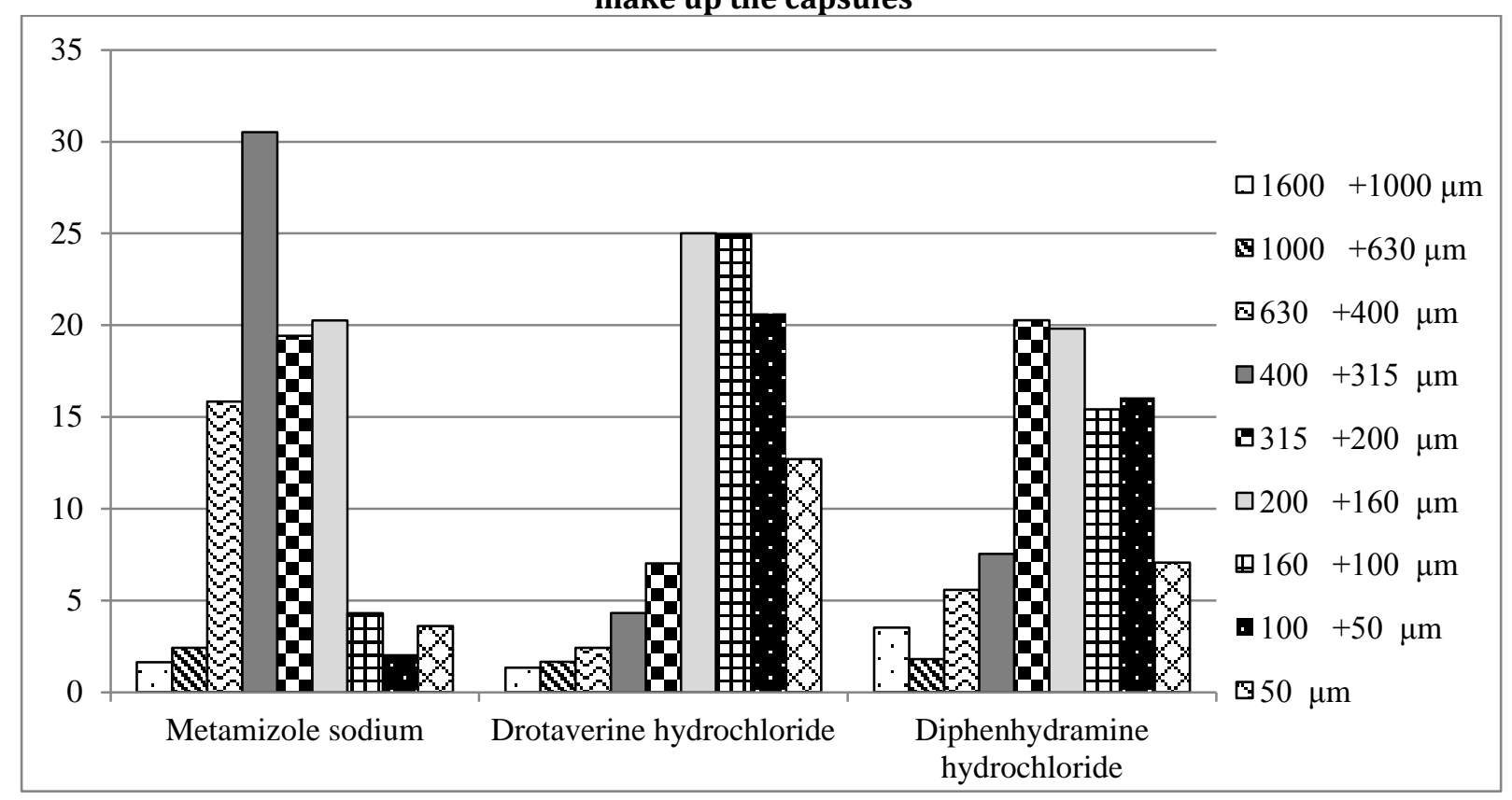

The results of studies conducted in similar fractional ranges showed that the largest amount of metamizole sodium $(82.01 \%)$ is in the range of $630+$ $200 \mu \mathrm{m}$, for which the average particle size is 395 $\mu \mathrm{m}$, for substances drotaverine hydrochloride $(83.3 \%)$ in the range of $-200+50 \mu \mathrm{m}$, in which the average particle size is $125 \mu \mathrm{m}$ and for diphenhydramine hydrochloride the largest number of particles $(71.55 \%)$ between fractions is $-315+50 \mu \mathrm{m}$, for which the average particle size is $182.5 \mu \mathrm{m}$.

According to the research results, the arithmetic mean values of the mass-average particle sizes were determined, which for sodium metamizole are 395 microns, drotaverine hydrochloride 125 microns and diphenhydramine hydrochloride 182.5 microns. Comparison of the obtained results with particle sizes showed that each of the four active substances exhibits a tendency to strong adhesion, as a result of which conglomerates are formed.

The results of studying the microscopic and technological properties of the substances metamizole sodium, drotaverine hydrochloride and diphenhydramine hydrochloride indicate the impossibility of obtaining capsules by the direct encapsulation of powders, since the unsatisfactory technological properties of the above active substances do not allow for the normal encapsulation of capsules that meet the requirements of the standards.

The study of the technological characteristics of the granulates of the combined preparation "Analfenon".

To obtain high-quality capsules, it was necessary to change the technological properties of the active substances that make up their composition in a positive direction. In practice, this is achieved by the use of auxiliary substances belonging to various groups, as well as the use of special technological operations leading to improved properties of the pressed mass.

At the next stage of the study, Analfenon granulate was obtained using the traditional technology of wet granulation by forcing a moistened mixture. As a granulating agent used a $2 \%$ paste of potato starch. Each component of the proposed combination means is weighed on an electronic balance. Taking into account the crystal structure, a solution of diphenhydramine hydrochloride in water was used. This ensures uniform distribution of the active substance in the drug. Diphenhydramine is dissolved in water in a ratio of 3: 5. Metamizole sodium, drotaverine hydrochloride, potato starch are mixed with a solution of diphenhydramine and granulated with a $2 \%$ potato starch paste. The mixture is dried in an oven for 15-20 minutes. Then the dried granules are passed through a sieve to obtain granules with uniform sizes. Then the granules are dusted with a powder of potato starch and calcium stearate. 
The technological characteristics of the obtained granulate samples were satisfactory, they are shown in Table 2.

Table 2

Technological characteristics of granules obtained by wet granulation

\begin{tabular}{|l|lc|}
\hline Indicator & \multicolumn{1}{c|}{ The value of indicators } \\
\hline Appearance & Granules yellow or yellow with a slightly greenish tint \\
\hline & $+2500 \mu \mathrm{m}$ & $-0,63$ \\
Fractional & $-2500+2000 \mu \mathrm{m}$ & $-16,81$ \\
composition, \% & $-2000+1000 \mu \mathrm{m}$ & $-23,67$ \\
& $-1000+500 \mu \mathrm{m}$ & $-34,18$ \\
& $-500+250 \mu \mathrm{m}$ & $-18,11$ \\
\hline Flowability, g /s & $-250 \mu \mathrm{m}$ & $-6,60$ \\
\hline Natural angle repose, degrees & & $4,20 \pm 0,13$ \\
\hline Bulk density, g/cm ${ }^{3}$ & & $28,0 \pm 2,0$ \\
\hline Compactibility & & $0,547 \pm 0,021$ \\
\hline Moisture content, \% & & $0,34 \pm 0,01$ \\
\hline
\end{tabular}

It is noted that with insufficient wetting of the mixture, the granulation process does not occur completely, a large amount of non-granulated material remains. In case of excessive moisture, granular enlargement and lump formation are observed. It has been experimentally established that the formation of granules is facilitated by the introduction of a granulating liquid in which drug substances are soluble. This leads to the adhesion of particles to each other due to the formation of liquid and then solid-phase bridges.

\section{CONCLUSION}

The method and mode of granulation "Analfenon" were selected, the effect of fractional composition, relative humidity and pressing pressure on the quality indicators of capsules "Analfenon" was studied. It was revealed that the fractional composition and technological characteristics of the granulate showed satisfactory results. The technology for producing granules with a positive result has been tested in a production environment.

\section{REFERENCES}

1. Emshanova SV, Abramovich RA, Potanina $O G$. Effect of the shape and particle size of substances on the quality of finished drugs. Development and registration of medicines. - 2014 No. 2 (7) .34-47

2. Barbara R. Conway. Pharmaceutical Manufacturing Handbook: Production and Processes. - S. 4 Normal Dosage Forms. 4.1 Solid Dosage Forms. 233-267.

3. Alekseev KV, Kedik SA, Blynskaya EV, Lazareva E E,. Uvarov NA, Alekseev VK, Tikhonova N. V. Pharmaceutical technology. Solid dosage forms:
Publishing House of ZOA "Institute of Pharmaceutical Technologies" - 2011. - 661.

4. Ravshanova SE, Yunusova XM, Ziyaev ShZ, Zufarova ZH. Assessment of the market for encapsulated drugs in the pharmaceutical market of the Republic of Uzbekistan. Materials of the III International Scientific and Practical Conference "Science of the XXI Century: Problems and Prospects." -Ufa. 2015: 77-80.

5. The Benefits of the soft galatine capsule as a dosage form - and popular product types Europe and the U.S. A. // Novel Drug Formulation Syst. Delivery Devices, Int. Semin., Riga, May 20-24, 1991, p. 2-8.

6. Kalpana P, Manish S, Dinesh S K, Surendra J K. Drug Invention Today. 2010. - Vol. 2, No. 7: 349357.

7. Ravshanova S E, Yunusova Kh M. Some features of selection of composition and technology of tablets "Analphenon". Medical science of the XXI century - looking towards the future. Materials of the international scientific-practical conference (67th annual), dedicated to the 80th anniversary of TSMU named after Abuali ibni Sino and "Years of development of the village, tourism and folk crafts. 2019; 3: 48-49. 